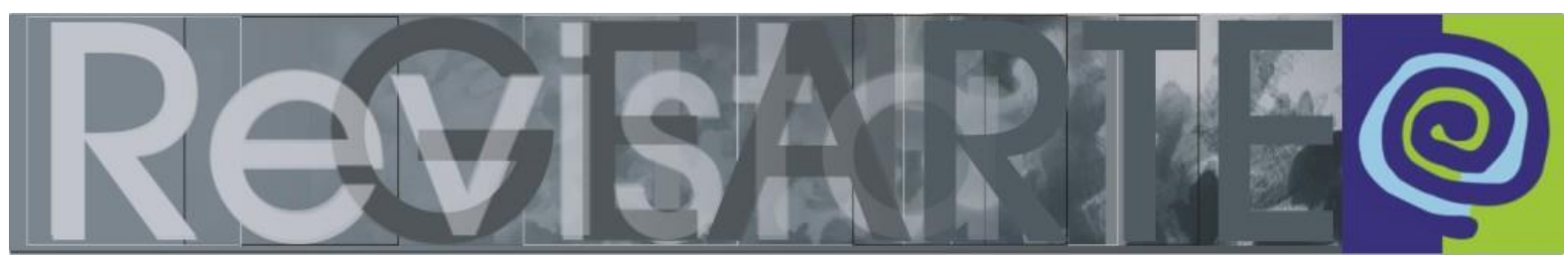

e-ISSN 2357-9854

\title{
O desenho no design de joias: processos e ensino
}

\author{
Engracia Maria Loureiro da Costa Llaberia (Universidade \\ Anhembi-Morumbi — UAM, São Paulo/SP, Brasil)
}

Ana Mae Barbosa (Universidade Anhembi-Morumbi — UAM, São Paulo/SP, Brasil)

RESUMO - 0 desenho no design de joias: processos e ensino - $O$ design de joias é área recente no Brasil e sua aplicação ainda pouco conhecida entre os empresários e mesmo entre os profissionais, por não haver ainda protocolos que estabeleçam normas ou indicações de encaminhamento de projeto. Sua metodologia ainda carece de estudos específicos e muito do que é observado dentro das empresas vem da prática dos profissionais em pesquisas referenciais, da criatividade e do próprio fazer da ourivesaria/joalheria. Busca-se na contemporaneidade identificar a forma de atuação do designer de produto na joalheria de modo a privilegiar a abordagem estratégica no lançamento de novos produtos. Neste artigo queremos dar destaque ao estudo do desenho dentro do processo de criação e produção seriada da joia e valorizar o desenho no ensino de Design de joias.

\section{PALAVRAS-CHAVE}

Desenhos de joias. Ensino de desenho. Design de joias. Ensino do design. Joalheria.

ABSTRACT - The drawing in the jewelry design: processes and teaching - Jewelry Design in Brazil is a recent area and its application still little known among businessmen and even among professionals, because there are still no protocols that establish norms or indications of project referral. Its methodology still lacks specific studies and much of what is observed within the companies comes from the practice of professionals in referential research, creativity and their own making of jewelry/goldsmiths. In the contemporaneity, it's fundamental to identify the product designer and his actions in jewelry to privilege the strategic approach for new products. In this article we want to highlight the study of drawing within creation process and serial production of the jewelry and to value it in the teaching of jewelry design.

\section{KEYWORDS}

Jewelry drawing. Drawing teaching. Jewelry design. Design teaching. Jewelry.

\section{Introdução}

Nas últimas décadas o design de joias se tornou assunto de interesse de muitos profissionais, tanto na produção artesanal como na produção industrial. Nesta, particularmente, os processos de criação e produção vieram se transformando de forma intensa, a partir do surgimento de novas tecnologias, exigindo adaptações no 
modo tradicional de fazer a joia. A produção seriada ganhou como aliados os novos programas digitais de desenho e prototipagem rápida'.

Design de joias diz respeito à atividade que se relaciona ao setor joalheiro no Brasil, composto por segmentos que são definidos pelos materiais e processos de produção que utilizam e que são definidos pela NCM, Nomenclatura Comum do Mercosul: o de joias preciosas (ou feitas em materiais preciosos), o das chamadas "joias" folheadas e o das bijuterias.

Entre eles despontou, com maior força nas últimas décadas, o que ficou conhecido como joalheria contemporânea. Sendo eminentemente artesanal, trouxe à cena o trabalho de artistas joalheiros com uma produção bastante significativa, de conteúdo conceitual e questionamentos em relação aos materiais e processos tradicionais da ourivesaria/joalheria. Dá-se muito mais ligada ao campo da artesania ${ }^{2}$ e da arte, onde a expressão pessoal está diretamente associada à definição da forma, processo do qual o desenho pode ou não fazer parte.

Por outro lado, muitas empresas ampliaram sua produção seriada de joias com cunho mais comercial, dando destaque ao setor de produção industrial, em todos os segmentos. Neles os desenhos são o meio de elaboração para o desenvolvimento criativo inicial das peças, assim como posteriormente para a representação de especificações técnicas para produção.

Note-se que a atividade joalheira contemporânea abarca diferentes modos de atuação e, particularmente no que se refere ao design, envolve o trabalho criativo de diferentes modos, do desenho de ilustração à modelagem, em uma enorme gama de variadas práticas. Tal como comenta Carles Codina3: "A joalheria é, de fato, uma

1 Prototipagem rápida - processo de modelagem de protótipos realizados em fresadoras e impressoras 3D, a partir de desenhos digitais.

2 Artesania - termo tomado por empréstimo do idioma espanhol, aqui utilizado para designar a atividade artesanal com especialidade de técnicas, definida também como ofícios tradicionais, tal como o joalheiro, o luthier (profissional especializado na construção e reparo de instrumentos de corda, como o violino), entre outros, na tentativa de diferenciá-la do artesanato, que no Brasil possui conotações de trabalho de menor valor técnico, como será visto adiante.

3 Carles Codina - joalheiro e professor da Escola Massana de Barcelona, autor do livro de referência, "A ourivesaria", no qual aborda suas técnicas de criação e produção artesanal de joias. 
realidade social única que pode ser entendida e interpretada por pontos de vista muito distintos como a joalheria comercial, a joalheria contemporânea, a alta joalheria, o ensino, etc." (CODINA, 2002, p. 94)

Priorizou-se o desenho, dentro do processo da joalheria nesta pesquisa, uma vez ser ele o elemento fundamental de comunicação em design. Assim, buscou-se identificar de que forma é utilizado nas diferentes fases dos processos de criação e de produção em todos os segmentos e modos de produção, artesanal ou industrial, e de que modo o profissional precisa estar habilitado para que seja direcionado seu ensino.

Figura 1 - Patrícia Cascino, Sketchbook. Estudos para produção industrial

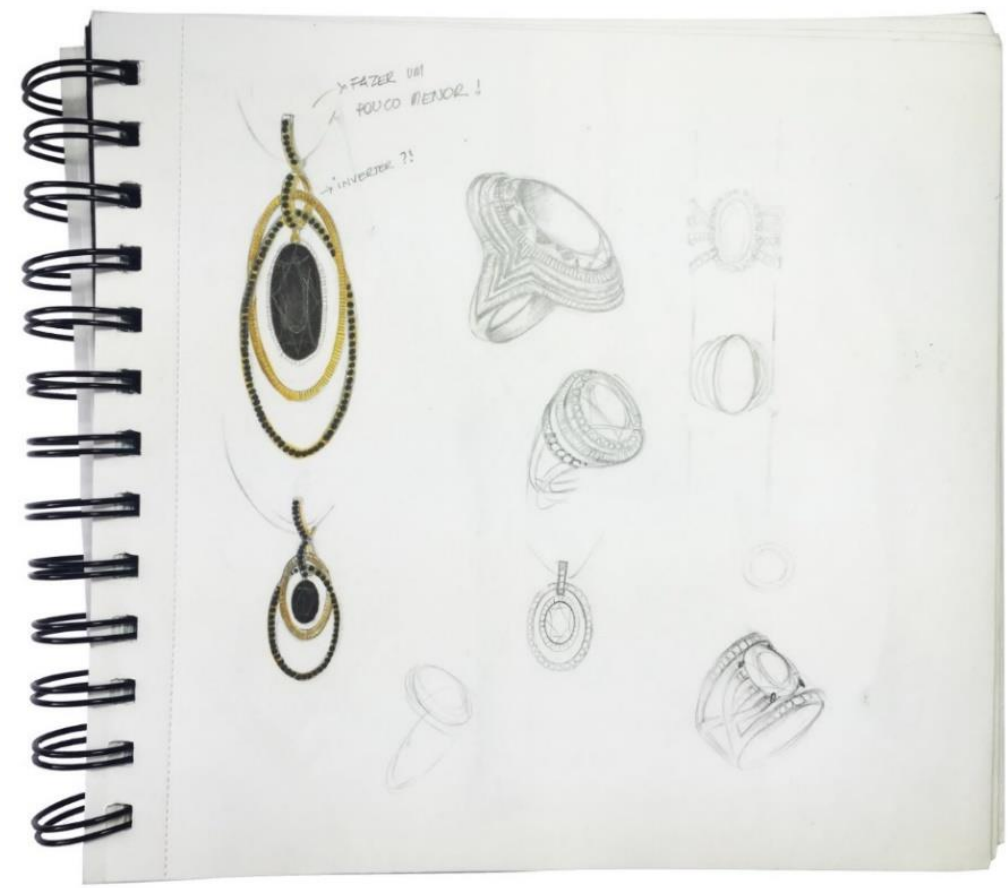

Fonte: Arquivo pessoal da designer.

Desta forma, procurou-se observar o trabalho de diferentes profissionais que atuam no setor na contemporaneidade, sendo assim possível analisar e fundamentar a importância do desenho em todo o processo de design da joia. Isto porque, mais do que simples representação ou ilustração de uma ideia, o desenho tornou-se a ferramenta principal de produção joalheira em algumas dessas atividades, particularmente na industrial. 
Neste aspecto, o design de joias assume uma outra dimensão na medida em que busca trazer para a joalheria o entendimento de projeto de produto e sua metodologia, aliado à visão estratégica, determinando um segundo momento do design de joias no Brasil, antes apenas atividade criativa.

A questão começa no próprio entendimento da nomenclatura adotada e que de muitos modos vem sendo apropriada por diferentes profissionais. Essa situação permanece, apesar das inúmeras tentativas de elucidação com a utilização do significado de industrial design ou desenho industrial, como foi registrado à época da fundação da ESDI (Escola Superior de Desenho Industrial), no Rio de Janeiro, em 1963 - primeira escola de desenho industrial no Brasil. Isso é comentado por Lucy Niemeyer, citando a carta escrita pelo Secretário de Educação e Cultura do então Estado da Guanabara, Carlos Flexa Ribeiro, destinada ao Governador Carlos Lacerda, em 09 de fevereiro de 1962 :

[...] os mais esclarecidos círculos brasileiros e mesmo o nosso pessoal dito de nível superior, na sua grande maioria, não sabe do que se trata, pensa que sabe. De fato, misturam design com drawing. Confundem também com desenho técnico e com desenho de máquinas. Permanecem sempre alheios ao caráter criado da atividade do designer como inventor de formas novas, adequadas às novas funções dos objetos. Custam por isso a reconhecer 0 papel do projetista industrial numa sociedade maquinofatureira. [...] misturam também o assunto com atividades artesanais, o que é um outro equívoco. [...] O designer terá que ser, assim, um arquiteto polivalente, capaz de projetar todos os tipos de produtos que a sociedade industrial precisa fabricar em série. [...] (NIEMEYER, 2007, p. 26).

Lucy acrescenta que outros usos da terminologia têm aumentado o malentendido em torno da profissão, uma vez que identificam atividades como hair designer, designer de sobrancelhas, designer de bolos, entre tantos, auxiliado pela desinformação da mídia, que colabora para essa confusão, não sendo difícil encontrarmos exemplos em revistas e programas de TV.

Sobre isso também comenta Luis Vidal Negreiro Gomes (1998, p. 96):

As incompreensões estariam por vir nas últimas décadas do século XX. Com o desenfreado uso de anglicismos, design tornou-se uma palavra da moda, superficial e efêmera que qualquer 'um', na atualidade, com qualquer habilidade 'estética' ou principalmente conhecedor de gráfica computacional, podia se intitular designer. 
Em relação à joia, em especial, assume-se que será um trabalho longo de esclarecimento, uma vez que são muito tênues os limites entre as diferentes atividades que adotaram essa nomenclatura, desde o ourives/joalheiro, o desenhista criativo, o modelista/"prototipador", o operador de programas digitais, o artesão que confecciona joias ou bijuterias com montagem de peças já existentes, a estilista de moda ou a pessoa de bom gosto que contrata um joalheiro e sugere formas, enfim, uma enorme variedade de profissionais, todos se apresentando como designers de joias.

Optou-se, assim, por alinhar a definição com o proposto por Lucy Niemeyer em seu livro Design no Brasil: origens e instalação, publicado em 2007, e que é a estabelecida no V ENDI (Encontro Nacional de Desenhistas Industriais), realizado em Curitiba em 1988, quando ficou decidida a adoção do nome da profissão como design e os profissionais como designers.

Design é atividade também definida pelo ICSID (International Council of Societies of Industrial Design), que define da seguinte forma a profissão:

Os designers industriais colocam o ser humano no centro do processo. Eles
adquirem uma profunda compreensão das necessidades dos usuários
através da empatia e aplicam um processo pragmático e centrado no usuário
para resolver problemas para projetar produtos, sistemas, serviços e
experiências. Eles são partes interessadas estratégicas no processo de
inovação e estão posicionados de forma única para preencher variadas
disciplinas profissionais e interesses comerciais. Valorizam o impacto
econômico, social e ambiental de seu trabalho e sua contribuição para cocriar
uma melhor qualidade de vida (ICSID, 2016).

Partindo deste princípio, o termo design está sendo aqui adotado de modo a identificar a atividade de projeto que se refere ao desenvolvimento de produtos direcionados a públicos específicos, com parâmetros de criação e produção, ditos industriais, do qual o desenho é parte integrante.

Procura-se categorizar na atualidade como designer de joias o profissional de design de produto que atua em joalheria, buscando um alinhamento com as propostas de reconhecimento profissional apresentadas por entidades representativas como a ADP (Associação de Design de Produto). Esse seria, dessa forma, o profissional especializado no desenvolvimento de produtos em coleções ou peças únicas para o 
setor joalheiro como um todo, considerando as particularidades envolvidas em cada tipo de produto e a contextualização com seu público e sua cultura.

Essa definição da atividade profissional visa esclarecer o mercado para que os profissionais possam se posicionar de acordo com suas habilidades e possibilidades de atuação, bem como para identificação pelas empresas dos profissionais que a ela se alinhem.

\section{Desenho e joalheria}

O desenho é uma das principais ferramentas das quais o designer se utiliza para o desenvolvimento do design de joias. Do momento inicial do processo de criação, a partir dos dados coletados na pesquisa referencial, o desenho participa como meio de simulação de objeto imaginado, sendo nas etapas seguintes a representação técnica do objeto a ser produzido, chegando à prototipagem com o uso dos recursos digitais.

Wucius Wong (1993, p. 41) considera que um bom desenho deve expressar visualmente da melhor maneira possível a essência de uma mensagem ou produto e acrescenta: "A linguagem visual constitui a base de criação do design".

O desenho de joias veio se desenvolvendo através do tempo, desde a joia enquanto objeto único, até a de produção industrial. Richard Sennett cita T.E. Heslop, historiador, que descreve essa mudança na forma de trabalho dos ourives: "Uma tendência a que hoje daríamos o nome de naturalismo, mais facilmente associada à pintura e à escultura, veio dominar de tal maneira que os ourives tiveram de cultivar a arte do desenho e da modelagem como nunca antes" (SENNETT, 2009, p. 83).

O trabalho no metal costumava definir a forma como um todo. Sennet aponta Benvenuto Cellini ${ }^{4}$ como tendo sido, talvez, o pioneiro nesse modo de trabalho.

Os desenhos de joias de determinadas épocas são hoje apresentados em museus, valorizados por si só, fazendo parte de importantes acervos, principalmente nas obras de nomes do Art Nouveau e do Art Déco, indicando através de suas formas as

4 Benvenuto Cellini - artista da Renascença italiana, escultor, ourives e escritor. 
características de estilo de seu tempo, possibilitando a historiadores a análise de determinados aspectos da sociedade. É possível encontrar desenhos de Lalique, Derraisme, Fouquet, Jacqueau e Mucha, um dos principais artistas do Art Nouveau. Os desenhos desses períodos em particular são hoje de grande valor e são comercializados em antiquários especializados como os Antiquaires du Louvre, em Paris.

Variando em técnicas e formas de apresentação, são também o registro das mudanças gradativas na maneira de representar-se tecnicamente uma joia. Utilizando canetas com bico de pena, nanquim, aquarelas e guache, tendo como suporte papéis especiais e depois os industrializados, a partir do século XIX, muitos desses desenhos traziam também indicações de detalhamentos para a produção.

Eram também usados como meio de catalogação e registro das criações, muitas vezes para apresentá-las para venda, como é o caso do Illustrated Jewelry Catalog: the new England Jeweler, de 1892, republicado em 1998 pela Dove Publications de Nova York.

Esta forma de representação foi a utilizada durante muito tempo. No entanto, a produção industrial trouxe outras exigências. Como a fabricação passou a depender de diferentes participantes com atribuições distintas na confecção de uma joia, a eficiência na comunicação dos detalhes projetados para se ter fidelidade nos resultados levou à exigência de desenhos cada vez mais técnicos.

Embora, os ateliês ainda trabalhem com desenhos simplificados, nos estágios de esboços em sua maioria, é nas fábricas que a excelência técnica na representação se fará cada vez mais necessária.

Como a prototipagem rápida é uma realidade que aos poucos toma conta do processo industrial, haverá também crescente demanda por profissionais capacitados a operá-los. Programas como o Rhinoceros e RhinoGold indicam com precisão, a partir do desenho, o peso da peça projetada, a quantidade de material necessária, preparação para cravações e, ao final, ainda possibilita a confecção do protótipo para reprodução por fundição. 


\section{Figura 2 - Eliania Rosetti - pingente em ouro. Desenho no RhinoGold e peça pronta}

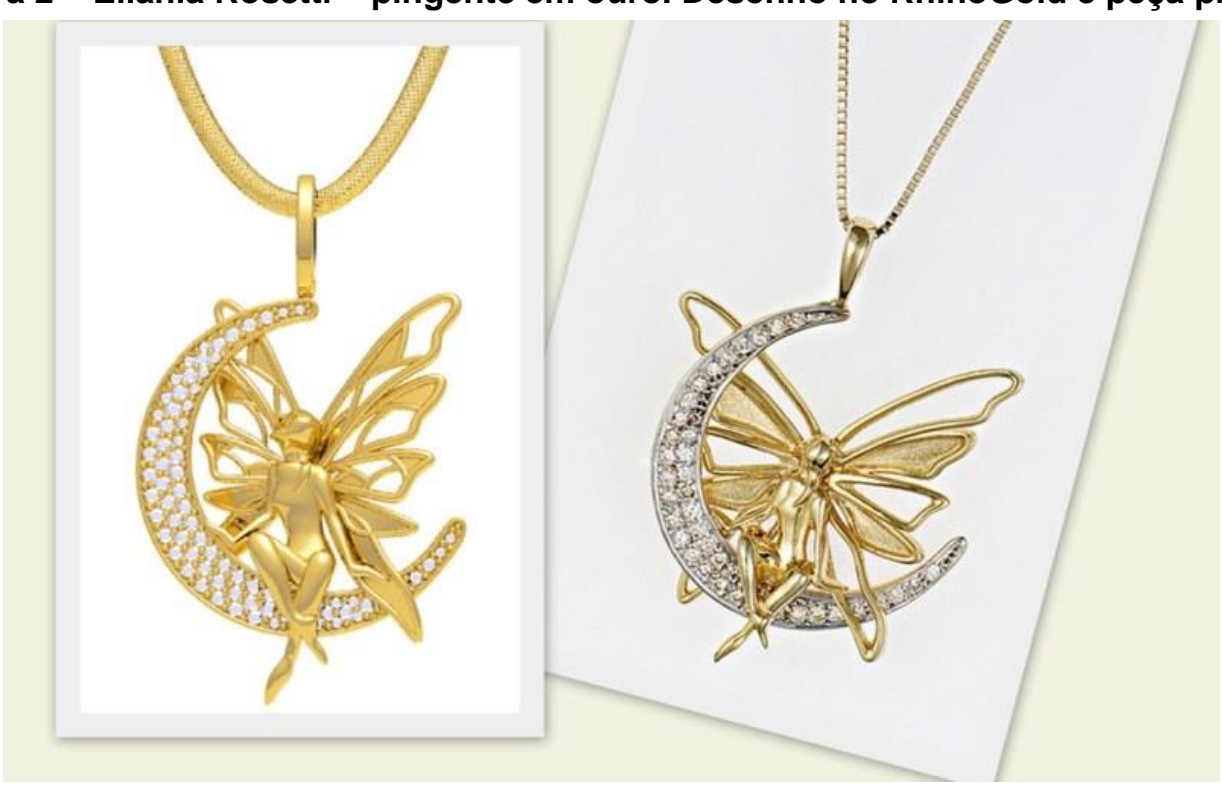

Fonte: Arquivo pessoal da designer.

O desenho digital revolucionou a joalheria, obrigando a uma revisão dos papéis dos profissionais que atuam na linha de produção. Wucius Wong aborda esse novo cenário:

O advento do computador não só revolucionou nossos meios de processamento de informação, como também possibilitou novos métodos para a criação do desenho. [...] com o desenvolvimento rápido nos últimos anos de programas gráficos e de periféricos a eles relacionados, o computador agora é capaz de realizar com grande eficiência a maior parte do trabalho de desenho normalmente feito a lápis, caneta e pincel. Deste modo, ele abre novos horizontes (WONG, 1993, p. 14).

E, apesar de o desenho digital estar cada vez mais sendo adotado, o desenho feito à mão ainda é bastante utilizado pelos profissionais de design, principalmente nas fases iniciais de estudos. Sobre isso afirma Alexandre Wollner ${ }^{5}$ que seu " software interno", mental, oferece mais possibilidades e ainda é mais rápido para os rabiscos e rascunhos do que o desenho no computador, só dele se aproximando no momento da definição de módulos e vetorização das imagens. Ao analisar-se o processo criativo de uma joia, de um modo geral, os rabiscos iniciais, os rascunhos, e esboços à mão livre, são utilizados quase que de forma unânime no trabalho dos profissionais, seja

5 Alexandre Wollner - desenhista industrial. Um dos fundadores da ESDI (Escola Superior de Desenho Industrial), no Rio de Janeiro em 1963, a convite do governo do estado, após sua estadia no curso da Escola de Ulm, HfG, Alemanha (anos 1951-52). Depoimento em ALEXANDRE Wollner, s/d. 
para posterior finalização no desenho manual ou em programas digitais (STOLARSKI, 2005).

Figura 3 - Maria Regina Mazza, joalheria autoral - pingente em ouro. Estudos em rascunhos, esboços e a peça pronta

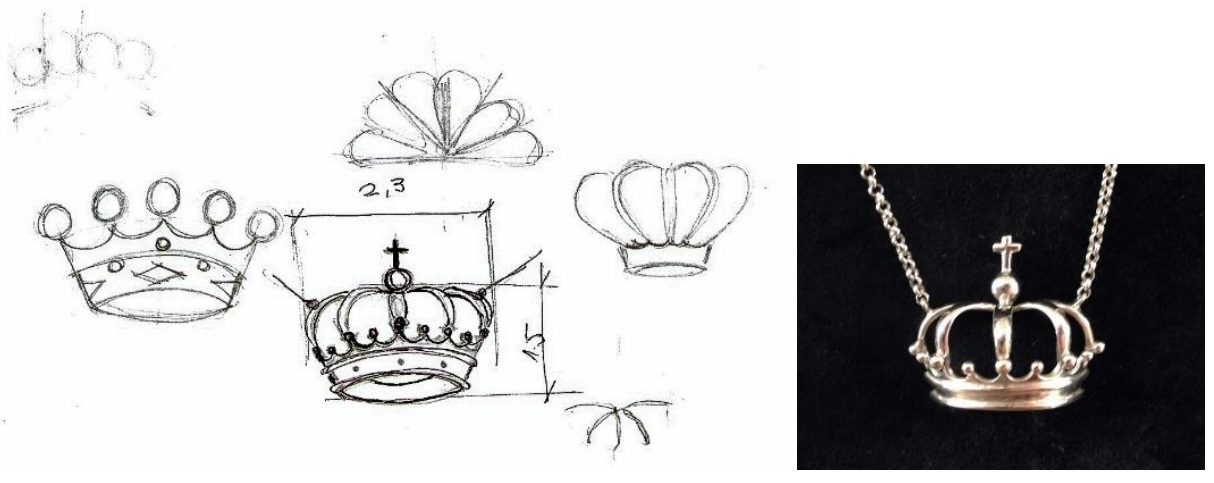

Fonte: Arquivo pessoal da designer.

Esses traços iniciais dificilmente podem ser substituídos por programas digitais, embora a tecnologia já tenha avançado para novas telas interativas sendo possível sobre elas executar o desenho manual. Para a maioria dos profissionais a manualidade no traço oferece possibilidades maiores e mais ágeis ao estudo formal. Nos sistemas industriais o desenho é arte, porque pressupõe o repertório do artista que cria e é mestria da técnica, do fazer a joia, antecipado em traços precisamente definidos.

Richard Sennett também comenta sobre essa interação do desenho e da produção manual com a tecnologia:

O desenho com a ajuda de computador pode servir como símbolo de um amplo desafio enfrentado pela sociedade moderna: como pensar a vida como artífices fazendo bom uso da tecnologia [...] pensar como artífice é mais que um estado de espírito: representa uma aguda posição crítica da sociedade (SENNETT, 2009, p. 56).

A joalheria, nesse momento, combina recursos que se originam nos dois processos de produção, o manual e o industrial. Na produção seriada, diversas fases ainda dependem do trabalho do homem, ainda que executadas em processos comuns à indústria. A tecnologia influenciou diretamente o tradicional fazer manual, levando o desenho a assumir o protagonismo da produção, particularmente na indústria, onde o trabalho do modelista vem sendo substituído pela prototipagem rápida. Alguns desses 
profissionais migraram sua forma de trabalhar, indo da bancada para as telas de computador, buscando a adaptação a essa forte tendência. No entanto, a preservação do ofício da ourivesaria/joalheria artesanal deve ser valorizada, destacando a habilidade de intervenção do homem sobre os materiais, resultando em formas com características pessoais.

Citando Edith Derdyk (1994, p. 20): "O desenho como linguagem para a arte, para a ciência e para a técnica é um instrumento de conhecimento, possuindo grande capacidade de abrangência como meio de comunicação e expressão."

O desenho é talvez o principal elemento de aproximação entre homem e máquina. Aponta a presença do homem no processo de design, desfazendo a impressão de que todo produto industrial é "robotizado" e desumano.

Como a exatidão repetitiva das máquinas tem uma precisão que a mão humana não pode imitar, a forma e composição dos produtos industriais raramente revela qualquer indicação da participação e personalidade da pessoa que os faz. [...], no entanto, são a manifestação de um processo de design humano, de concepção, juízo e especificação traduzidos em realidade tangível, material (HESKETT, 2006, p. 10).

Através do desenho traduz-se aquele que se expressa em distintas fases e tipologias de traços que, quando contextualizados no projeto de design, revelam o ser humano por trás do produto, como artista e como técnico.

Falou-se da metodologia de projetos de design na qual o desenho se insere, mas cabe lembrar que não há ainda um estudo específico com consenso sobre qual se adapta à joalheria, em que poderão haver diferentes etapas de acordo com o tipo de atividade de criação e produção de joias.

A estrutura básica da metodologia dos projetos de design de produto, como a proposta por Bruno Munari de forma linear, pode ser adaptada à produção joalheira, inicialmente.

Criatividade não significa improvisação sem método: essa maneira apenas se faz confusão e se cria nos jovens a ilusão de se sentirem artistas livres e independentes. A série de operações do método projectual é feita de valores objectivos que se tornam instrumentos de trabalho nas mãos do projectista criativo (MUNARI, 1981, p. 21). 
Sua estrutura básica permeia a ordenação das etapas essenciais e permite entender em quais delas o desenho participa no seu desenvolvimento.

Sendo assim, o cuidado em relação ao ensino do desenho deve ser mais do que nunca valorizado, tanto no seu sentido artístico como no técnico, uma vez que todo o desenvolvimento de projeto dependerá em maior ou menor grau de sua utilização, visando a atuação na linha de produção.

\section{O ensino do desenho de joias no Brasil}

Nessa trajetória da joalheria brasileira recente, dos anos de 1970 para cá, quando a produção nacional começa a se desenvolver, muitos cursos foram surgindo em escolas dedicadas à formação de ourives e joalheiros. No entanto, em sua maioria esses profissionais de voltaram à produção artesanal e pouco se registrou em relação à formação dos profissionais para atuar junto às indústrias.

São Paulo, Rio de Janeiro e Minas Gerais foram locais que se destacaram com o surgimento de diversas escolas, marcando essa grande safra de joalheiros e designers, algumas permanecendo até a contemporaneidade. Dentre esses pioneiros alguns se tornaram professores, tanto da prática de bancada da joalheria artesanal, como de desenho.

Por ser uma área de atividade nova, não havia critérios para o ensino desta representação que se dedicava em geral à apresentação de propostas aos clientes e encaminhamento para a produção. Por esse motivo não foi possível identificar uma cultura em relação ao desenho de joias no Brasil. É também recente entre nós o surgimento de publicações disponíveis tratando do assunto. As publicações internacionais durante muito tempo foram as referências utilizadas. Apenas nesta última década passou-se a observar um crescente número de livros, apostilas e pesquisas acadêmicas especificas, nacionais

As primeiras escolas em geral apresentavam os cursos como Design de Joias, quando na verdade tratavam do desenho e não do processo de projeto, com a complexidade do conjunto das disciplinas que compõem o conteúdo necessário para o desenvolvimento de um produto. Também não chegavam ao desenho técnico. Eram 
ensinadas formas esquemáticas de desenho de uma joia, adaptadas do desenho de objetos em geral, servindo como base para elaboração mínima em croqui ${ }^{6}$, suficiente para comunicar o que seria passado para a produção. Isto porque o curso era, em geral, procurado por pessoas que pretendiam apenas desenvolver suas peças e o rigor técnico na representação não era requerido. Assim, a maioria era dedicado à ilustração da joia em técnicas quase sempre mistas, com grafite, lápis de cores, guache, aquarela e canetas.

No entanto, o desenho de produção exigiria a representação de vistas mínimas necessárias e suficientes para o entendimento da peça, contendo especificações e indicações de materiais de modo a orientar o processo produtivo em fichas técnicas.

Assim, não basta a habilidade de desenhar artisticamente, mas a de desenhar tecnicamente, o que exige também o conhecimento do ofício da ourivesaria/joalheria, sem o qual há o risco de projetar-se o inviável de ser produzido.

A questão do desenho para produção veio sendo abordada ao longo do tempo no Brasil, como forma de preparo do estudante para o trabalho na indústria, embora o setor produtivo joalheiro não tenha se especializado nessa direção.

Com a necessidade de acompanhar as novas tecnologias e as relações entre os vários atores do processo de produção, cada vez menos informal, esse desenho também precisou acompanhar a profissionalização crescente do setor, especialmente no que se relaciona à produção industrial.

As escolas formais de ensino do começo do século $X X$ buscaram implantar o resultado de estudos e propostas de nomes como Theodoro Braga, Fidelis Reis e Rui Barbosa, incentivadores do ensino do que muitos já entendiam como o desenho industrial que era o desenho voltado à aplicação prática. Destaque-se os projetos de Fidelis Reis, deputado mineiro, com "o objetivo de preparação para o trabalho" (BARBOSA, 2015, p. 124) e, posteriormente Valnir Chagas, seguindo o Projeto Fidelis

6 Croqui (croquis) - desenho feito à mão, definido brevemente a forma de uma ideia. O senso comum adotou tanto a nomenclatura "esboço" como "croqui" com o mesmo significado. Mas existem diferenças formais que se pode identificar entre eles, indicadas pela ABNT - NBR 10647 - Desenho, quanto ao grau de elaboração. 
Reis, que tentou profissionalizar o Ensino Médio no Brasil, mas não obteve sucesso. Esse tema também foi tratado por Theodoro Braga, respeitado como professor de desenho e designer, que, em seu discurso de 1923 - A Educação - afirmava que o ensino do desenho deve ser voltado para a prática: construir primeiro a forma pela linha para depois construí-la pelo relevo (ibidem). Tratou também sobre o desenho de criação, incentivando a utilização de referências brasileiras como tema, com um olhar para nossa fauna e flora, apontando ser esse um meio de combater a cópia de padrões estrangeiros. Destacava a riqueza dos elementos naturais brasileiros como base suficiente para a criatividade dos nossos artistas e designers. Deixou um trabalho bastante "inventivo, original e nacional, como pretendia" (ibidem, p. 112).

Tem-se a lamentar o quanto foi menosprezado o ensino da arte $\mathrm{e}$ especificamente do desenho, ao menos nos últimos 30 anos, nos diferentes estágios do ensino formal, o que fez com que se tenha hoje pouco preparo dos alunos para encarar os desafios de certas áreas como o design de produto e até mesmo a Arquitetura.

No que se refere ao design, desde as primeiras escolas no Brasil, tem-se o entendimento da importância do domínio das disciplinas de desenho como base para o processo de desenvolvimento de produtos, com a visão multidisciplinar que faz parte do ensino do design.

Neste contexto, o ensino do desenho deverá acompanhar a necessidade relativa a cada fase, desde o registro de estudos em rabiscos, rascunhos, à definição dos esboços, desenho técnico, ilustração, permeando todas as etapas em que se faz necessária sua utilização para representação da ideia.

Por esse motivo passou-se a analisar o conteúdo que veio sendo aplicado e o que seria adequado à formação desse profissional.

Como ação institucional, foi estruturado em 2013 o Projeto Ferramentas do Design na AJESP (Associação dos Joalheiros do Estado de São Paulo), voltado à informação geral e formação de designers, elaborado à luz das novas tecnologias e das novas demandas de mercado. Particularmente no que diz respeito ao desenho, 
nesse projeto as disciplinas que estão sendo oferecidas já contemplam a complexidade que compõe o projeto de design, em sua função estratégica para as empresas. Como curso livre, é composto por módulos independentes de disciplinas que ofereçam uma visão abrangente de produto na joalheria.

\section{Conclusão}

O desenho de joias, por ser área recente, como exposto, ainda carece de normalização e critérios para sua execução. Desenvolveu-se nas últimas décadas de modo informal, a partir das experiências dos diversos profissionais que se dedicaram à arte da joalheria e foi registro de muitos momentos da sociedade como um todo.

Com a entrada de novas tecnologias e o crescimento da produção industrial, sua profissionalização se tornou necessária, de modo a alcançar-se melhor entendimento entre os diversos atores que compõem o panorama da joalheria brasileira na contemporaneidade.

Assim o ensino do desenho de joias ganha proeminência nas novas perspectivas de profissionalização do setor. É arte e técnica de representação de um produto. Como arte, traduz a criação através de técnicas de simulação de propostas para novos adornos. Como técnica, é registro e determinação de detalhamentos fundamentais à execução da joia. No ensino do desenho merece atenção não somente o processo criador, mas também as normas técnicas, de modo a estar alinhado aos procedimentos já adotados em outras áreas do desenho de produtos, bem como à metodologia comum aos projetos de design de produto.

A joalheria mudou particularmente no século $X X$, acompanhando as transformações sociais, e continua em mutação no século XXI, considerando as tendências de comportamento do consumidor/usuário. O desenho da joia continuará a acompanhá-la nesse trajeto e dela será seu melhor tradutor.

\section{Referências}

ALEXANDRE Wollner e a formação do design moderno no Brasil. [Filme-vídeo]. Direção de André Stolarski. São Paulo, s/d. 84 min., color, son. Disponível em: https://youtu.be/s7LOZLMRRO0. 
BARBOSA, Ana Mae. Redesenhando o desenho: educadores, política e história. São Paulo: Cortez, 2015.

CODINA, Carles. A ourivesaria. Lisboa: Estampa, 2002.

DERDYK. Edith. Formas de pensar o desenho: desenvolvimento do grafismo infantil. São Paulo: Scipione, 1994, p. 20.

GOMES, Luiz Vidal Negreiros. Desenhando: um panorama dos sistemas gráficos. Santa Maria, RS: UFSM, 1998.

HESKETT, John. Desenho Industrial. Rio de Janeiro: José Olympio, 2006.

ICSID - International Council of Societies of Industrial Design. Definição de Design Industrial e de designer. Disponível em <http://wdo.org/about/definition/> Acesso em: out 2016.

Illustrated Jewelry Catalog, 1892: the New England Jeweler. New York: Dove Publications Inc., 1998.

MUNARI, Bruno. Das coisas nascem coisas. Lisboa: Edições 70, 1981.

NIEMEYER, Lucy. Design no Brasil: origens e instalação. Rio de Janeiro: 2AB, 2007.

SENNETT, Richard. O artífice. Rio de Janeiro: Record, 2009.

STOLARSKI, André. Alexandre Wollner e a formação do design moderno no Brasil. São Paulo: Casac Naify, 2005.

WONG, Wucius. Principles of form and design. Nova lorque: John Wiley \& Sons, 1993.

\section{Engracia Maria Loureiro da Costa Llaberia}

Doutora em Design pela Universidade Anhembi Morumbi, Laureate International Universities. Tese defendida e aprovada em dezembro de 2016. Mestre em Design pela Universidade Anhembi Morumbi. Graduada em Desenho Industrial pela ESDI, Escola Superior de Desenho Industrial / Universidade do Estado do Rio de Janeiro, UERJ, com habilitação em Design de Produto e Programação Visual. Bacharel em Comunicação Social, Publicidade e Relações Públicas, pela Universidade Estácio de Sá/ RJ. Docente do IED, Istituto Europeo di Design (2005-2006). Docente na Universidade Anhembi Morumbi nos cursos de Design e Arquitetura e Urbanismo (2008-2016). É designer credenciada pela ADOR, Associazione Designers Orafi, de Milão, Itália, desde 1993.

E-mail: gracia.costa02@gmail.com

Currículo: http://lattes.cnpq.br/5354204773120931

\section{Ana Mae Barbosa}

Possui graduação em Direito - Universidade Federal de Pernambuco (1960), mestrado em Art Education - Southern Connecticut State College (1974) e doutorado em Humanistic Education - Boston University (1978). Atualmente é Professora Titular aposentada da Universidade de São Paulo e professora da Universidade Anhembi Morumbi. Tem experiência na área de Artes, com ênfase em Arte/Educação, atuando principalmente nos seguintes temas: Ensino da Arte e contextos metodológicos, História do Ensino da Arte e do Desenho, Ensino do Design, Administração de Arte, Interculturalidade, Pedagogia Visual, Estudos de Museus de Arte, Mediação Cultural e Estudos Visuais.

E-mail: anamaebarbosa@gmail.com

Currículo: http://lattes.cnpq.br/1650414096296319

Recebido em 5 de junho de 2017 Aceito em 11 de outubro de 2017 